\title{
THE ATMOSPHERE AND IONOSPHERE OF JUPITER
}

\author{
S. K. Atreya and T. M. Donahue \\ Department of Atmospheric and Oceanic Science, Space Physics Research \\ Laboratory, Ann Arbor, Michigan 48109, U.S.A.
}

\begin{abstract}
The properties of the atmosphere of Jupiter are reviewed in the light of observations carried out by the Voyager mission. Solar occultation measurements in the ultraviolet show that the temperature of the upper atmosphere $1 \mathrm{~s} 1100 \pm 200 \mathrm{~K}$, an apparent increase of about $30 \%$ from the value obtalned by the Ploneer mission in 1973. Stellar occultation in the ultraviolet indicate that the temperature gradient in the thermosphere is about $1 \mathrm{~K} \mathrm{~km}^{-1}$. These results pose problems for candidate heating mechanlsms because the heat input required is large $(0.5$ ergs $\mathrm{cm}^{-2} \mathrm{~s}^{-1}$ ) and must be deposited at high altitudes. Solar EUV, inertia gravity waves and particle and ton precipitation appear to be unsatisfactory mechanisms for the equatorial thermosphere. Joule heating remains a possibility. For Joule heating to be a viable mechanism, differential wind of several hundred meters per second between the ions and neutrals is required throughout the entire fonosphere. The stellar occultation experiment also provides a determination of the altitude of the homopause and the eddy diffusion coefficient there of about $(1-2) \times 10^{6} \mathrm{~cm}^{2} \mathrm{~s}^{-1}$. This result is consistent with the value deduced from the helium $584 \AA$ airglow emisston rate based on the evidence from infrared data that the $\mathrm{He} / \mathrm{H}_{2}$ ratio is $0.10 \pm$ 0.03 . A very large solar cycle variation in the atomic hydrogen Lyman alpha airglow emission rate is discussed. The stellar occultation data also provide information concerning hydrocarbons in the atmosphere. The volume mixing ratios of $\mathrm{CH}_{4}$ and $\mathrm{C}_{2} \mathrm{H}_{6}$ are found to be $2.5 \times 10^{-5}$ and $2.5 \times 10^{-6}$ at $5 \mu \mathrm{b}$ level, while the upper Ifmit for $\mathrm{C}_{2} \mathrm{H}_{2}$ at $10 \mathrm{\mu b}$ level is $5 \times 10^{-6}$. Voyager IR data yield the volume mixing ratios deeper in the stratosphere to be $(1.4 \pm 0.45) \times 10^{-3}, 5 \times 10^{-6}$, and $3 \times 10^{-8}$ to $10^{-7}$ for $\mathrm{CH}_{4}, \mathrm{C}_{2} \mathrm{H}_{6}$ and $\mathrm{C}_{2} \mathrm{H}_{2}$ respectively. The $\mathrm{CH}_{4}$ mixing ratio is thus $1.5 \pm 0.5$ times the value one would expect for a solar composition ratio of the elements.
\end{abstract}

The equatorial electron density profile determined by Voyager radio occultation can be explained if ion molecule reactions between $\mathrm{H}^{+}$and vibrationally excited $\mathrm{H}_{2}$ at high temperatures are fast enough. Temperature dependence of these reactions also accounts for an observed ionospheric diurnal variation. The high latitude ionosphere indicates possible precipitation of high energy particles in the region mapped by the Io plasma torus.

\section{INTRODUCTION}

Much of what is presently known about the upper atmosphere and ionosphere of Jupiter has been made possible by the successful observations carried out on the two recent Voyager spacecraft. The ultraviolet spectrometer (UVS) and the radioscience subsystem (RSS) provided the principal data, and the gaps in these data were often bridged by the infrared (IRIS) and imaging science (ISS) measurements. The pre-Voyager view of Jupiter's upper atmosphere and ionosphere is rather rudimentary and has already undergone radical changes. For completeness and continuity we will provide a brief overview of the pre-voyager observations and the theoretical calculations; fairly comprehensive reviews of the subject before the Voyager observations can be found in Strobel (1975, and 1979), and Atreya and Donahue (1976 and 197y). The important aeronomical questions about the upper atmosphere concern the thermal structure of the upper atmosphere and its implica- 
tions for the atmospheric energetics; the composition of the atmosphere and the strength of mechanical mixing; and sources and sinks of lonization. The following discussion is a development of these basic themes.

\section{THERMAL STRUCTURE}

Optical observations from the ground, from sounding rockets and from Pioneer spacecraft all indicated an ammonia cloud top temperature of about $150 \mathrm{~K}$ where the pressure was about $600 \mathrm{mb}$, with a temperature inversion between 10 and $100 \mathrm{mb}$ in the troposphere (see review by Hunten, 1976). The temperature rose to a nearly constant value of $160-170 \mathrm{~K}$ at a pressure level of about 5 to $10 \mathrm{mb}$. The occultation of the star $\beta$ Sco in the visible gave a temperature of about $170 \pm 30 \mathrm{~K}$ at $10 \mathrm{\mu b}$ (Hunten and Veverka, 1976). Measurement of the topside ionospheric electron density profile by radioscience techniques from Pioneers 10 and 11 gave the first Indication of a warm plasma - on the order of $850 \mathrm{~K}$ (Fjeldbo, et al., 1975, and 1976). Theoretical considerations for both cold and hot exospheres by Henry and McElroy (1969) and Nagy et al. (1976) Indicated virtually no disequilibrium between electron, ion and neutral temperatures in the vicinity of the electron density peak. This is due to the fact that above the peak, the electrons lose energy in collisions with the major ion $\mathrm{H}^{+}$. The warmer $\mathrm{H}^{+}$in turn loses energy in resonance charge exchange with $\mathrm{H}$, and in collisions with $\mathrm{H}_{2}$. Below the peak, the electrons lose energy in rotational excitation of $\mathrm{H}_{2}$. Thus, even before the Voyager observations, one could speculate with reasonable certainty that the upper atmospheric temperature should be high. No information on the thermal structure in the upper stratosphere, mesosphere and thermosphere was avallable (except for temperatures at $1 \mu \mathrm{b}$ and about $10^{-11}$ bar).

The Voyager 1 solar occultation experiment carried out at a range of about $7 \mathrm{R}_{\mathrm{J}}$ $\left(1 \mathrm{R}_{\mathrm{J}}=71,300 \mathrm{~km}\right)$ yielded the first measurement of the upper atmospheric neutral temperature (Atreya, et al., 1979a). Continuous absorption of the solar ultra$v$ lolet radiation in the 600-800 range by atmospheric molecular hydrogen can yleld the value of the scale height of the absorbing region. It has been found that such an absorption occurs over a large helght interval (Fig. 1) Indicating a large upper atmospheric scale height. Indeed, the analysis of the data yleld a temperature of $1450 \pm 250 \mathrm{~K}$ at an atmospheric density level of $3 \times 10^{7}$ molecules $\mathrm{cm}^{-3}$ (Atreya, et al., 1979a) which corresponds roughly to 1500-2000km above the ammonia cloud tops. Because of the large range of the spacecraft, the large angular diameter of the sun $\left(0.1^{\circ}\right.$ at $\left.5 \mathrm{AU}\right)$, and the non-uniformity of the ultraviolet distribution of the disc of the sun, the statistical uncertainty in the above determination is large. The Voyager RSS observations of the electron density in the equatorial region performed within hours of the solar occultation experiment yield a plasma temperature in the topside lonosphere which is on the order of $1300 \mathrm{~K}$ (Eshleman, et al., 1979a). The solar and radio occultation measurements both probe the troplcal upper atmosphere almost simultaneously and confirm the theoretical predictions of energy equilibrium between the plasma and neutral gas in the upper atmosphere.

The temperature up to the $2 \mathrm{mb}$ level was determined by the IRIS (Hanel, et a1.,1979) and RSS measurements, and except for considerable structure, agreed with results 


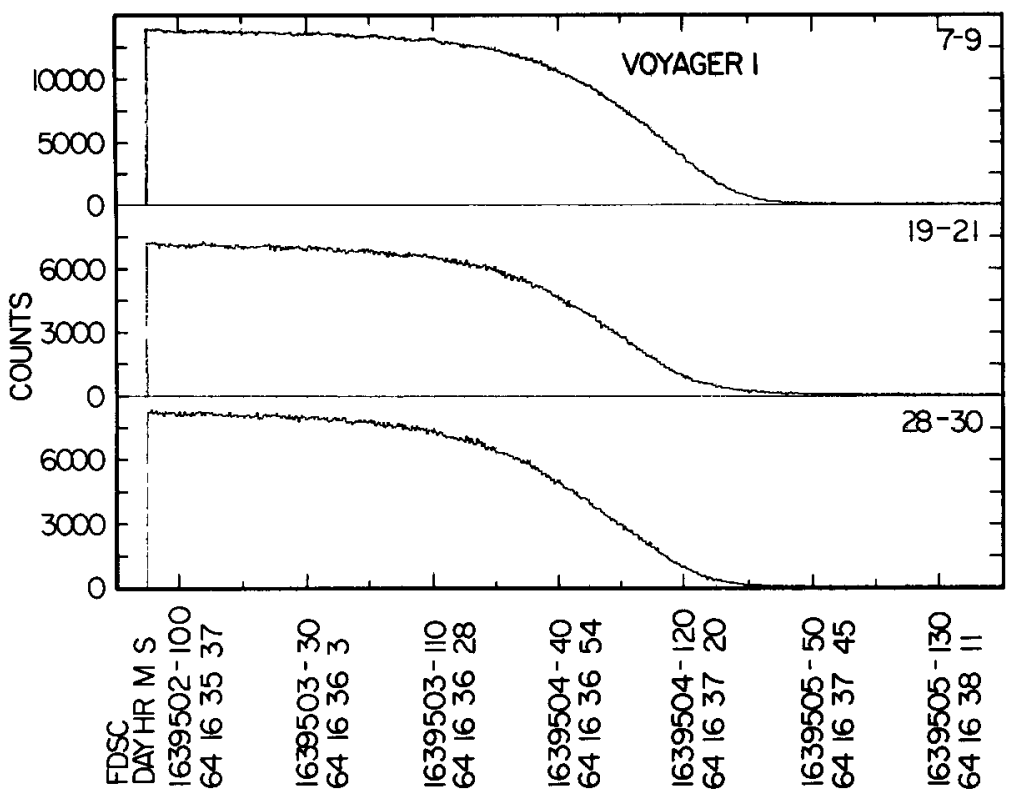

Fig. 1. Counting rates in three representative sets of channels: 7-9 (590-618 ), $19-21(665-692 \AA)$, and $28-30(702-729 \AA)$ as a function of time during the Voyager 1 solar occultation experiment (Atreya, et al., 1979a). The unattenuated signal represents solar flux in the appropriate channels before continuum absorption by $\mathrm{H}_{2}$ in the atmosphere.

of earlier observations pertaining to somewhat lower pressure levels. The temperature above the helght of $1 \mathrm{mb}(\sim 160 \mathrm{~km})$ was determined from an ultraviolet occultation of star aLeo monitored by Voyager 2 from a range of $27 R_{T}$. Figure 2 is in illustration of the progressive absorption in Jupiter's atmosphere of

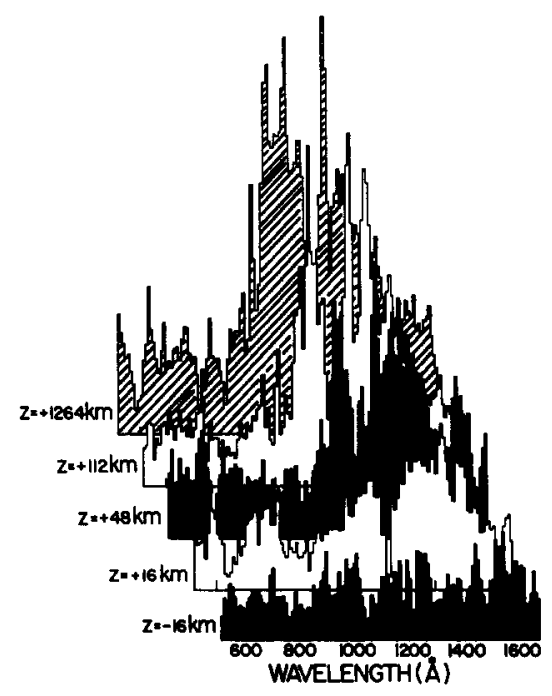

Fig. 2. Progressive absorption of the $\alpha$ Leo spectrum as the tangent ray height descends in the Jovian atmosphere. The zero of the altitude reference is $200 \mathrm{~km}$ above the ammonia cloud tops. 
the stellar light above the Lyman continuum cut off limit. The first spectrum taken $1264 \mathrm{~km}$ above the total extinction level is an unattenuated stellar spectrum as measured by the UVS. The absorption increases as the tangent height 1s lowered.

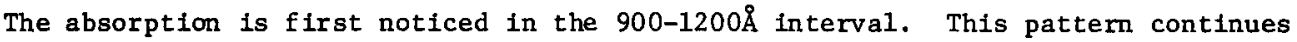
over about $500 \mathrm{~km}$. Within a few seconds after that, the entire long wavelength portion $(\lambda>1200 \AA)$ is rapidly absorbed, while the line of sight proceeds through the last tens of kilometers before total extinction occurs. Fig. 3 adapted from Sandel, et al. (1979) shows two distinct spectral regions of the absorption. The upper panel depicts absorption over a large height range by $\mathrm{H}_{2}$ in 1 ts Lyman and Werner bands while the lower panel shows a rapld absorption by various hydrocarbons in the deep atmosphere where the temperature is low. The details of the above

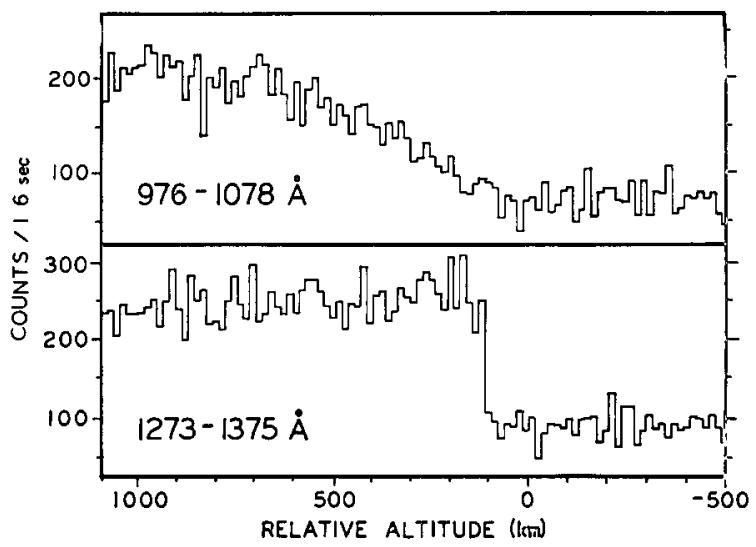

Fig. 3. Representative sets of a Leo stellar occultation data (Sandel, et al., 1979). The upper panel shows absorption in the $\mathrm{H}_{2}$ Lyman and Werner bands and is indicative of a large scale height in the upper atmosphere. Absorption in $\lambda>1200 \AA$ sets in quickly in the deeper atmosphere where $\mathrm{CH}_{4}$, and $\mathrm{C}_{2} \mathrm{H}_{6}$ densities become large.

stellar occultation data analysis have been presented by Festou, et al. (1980). These data yield temperature and atmospheric density profiles from $160 \mathrm{~km}$ to about $1750 \mathrm{~km}$ above the ammonia cloud tops. On combining the mesospheric and thermospheric data of the $\alpha$ Leo stellar occultation with the solar occultation data in the exosphere, and IRIS and RSS data in the stratsophere and the troposphere one arrives at a composite thermal structure as shown in Figure 4 . The results are valid for tropical latitudes; only fragmentary data are available for the other latitudes.

The thermospheric temperature profile in Fig. 4 looks simflar to the earth's thermosphere. Deeper in the atmosphere, except for a well-defined tropopause, there is virtually no resemblance to the terrestrial thermal structure. Indeed, an earthlike mesopause on Jupiter is not supported by the observations. Unlike the earth, Jupiter receives a minute amount of energy from the sun and its upper atmospheric energetics are not expected to be controlled by solar EUV. There are several aspects of the Jovian upper atmospheric temperature structure which need to be discussed. The exospheric temperature is high, and it has increased by more than $50 \%$ from the time of the Pioneer observations in 1973. Although the Pioneer observations were made near the solar minimum, and the Voyager observations near 


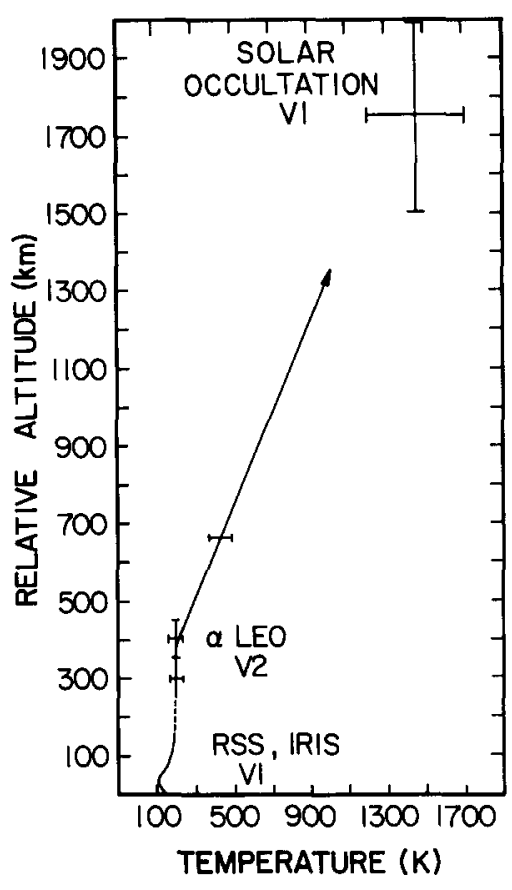

Fig. 4. Equatorial thermal profile resulting primarlly from the Uvs solar and stellar occultation data. Temperature from the cloud tops up to $1 \mathrm{mb}$ level ( $150 \mathrm{~km})$ is obtained by IRIS and RSS experiments. Linear extrapolation between the IRIS and UVS data is indicated by broken line. Altitudes are measured from the ammonia cloud tops. The exospheric temperature reaches a value of $1100 \pm 200 \mathrm{~K}$ consistent with the further analysis of the Atreya, et al. (1979a) solar occultation data. Readers wishing to use this figure must consult Atreya, et al. (1980) and Festou, et al. (1980) for further details.

solar maximum, it is difficult, for the reason cited, to make a case for direct correlation of the increased solar activity with the increased temperature. In the following paragraphs are examined several possibilities which could lead to elevated thermospheric temperatures in the absence of a large solar EUV source.

In the B Sco occultation data (E1liott, et al., 1974) oscillations in the upper atmospheric temperature structure were observed. These oscillations are reminiscent of vertically propagating inertia gravity waves which generally break up five to ten scale heights above the homopause; there they could either be reflected or dissipate some or all of their energy in the form of heat. French and Gierasch (1974) calculated that these waves carry up to 3 ergs $\mathrm{cm}^{-2} \mathrm{~s}^{-1}$ of energy. Atreya and Donahue (1976) and Atreya, et a1., (1979a) found by solving the one dimensional heat conduction equation that if all this energy were available for heating the atmosphere, a temperature between 1000 and $1500 \mathrm{~K}$ could easily be attained nearly 150 to $300 \mathrm{~km}$ above the homopause (assumed to be at a density level of $10^{11}$ to $10^{13} \mathrm{~cm}^{-3}$ ). The Voyager ISS data also indicated the presence of planetwide inertia waves (Hunt and Muller, 1979). The dissipation of the Inertia gravity waves would result in a large temperature gradient deep in the atmosphere; the observations (Fig. 4), on the other hand, indicate a rather low $\left(<1 \mathrm{~K} \mathrm{~km}^{-1}\right)$ lapse rate in the thermosphere. Moreover, there is no reason to expect effects associated with inertia gravity waves to vary during the solar cycle. 
Another possibility for heating of the upper atmosphere 1s the penetration of magnetospheric electrons - soft or hard. According to a mechanism proposed by Hunten and Dessler (1977), magnetospherfc soft electrons can, in princlple heat the upper atmosphere. A heat source of some 0.5 ergs $\mathrm{cm}^{-2} \mathrm{~s}^{-1}$ would be needed to produce temperatures of about 1000K. Although Hunten and Dessler suggested some mechanisms for producing the electrons there is a serious problem in finding a source with sufficient strength to produce the required electron flux. Nevertheless, there is some evidence to support their suggestion, although even that is not unambiguous. The Voyager UVS detected dayside planetwide emissions of the $\mathrm{H}_{2}$-Lyman and Werner bands which are excited by low energy ( $\left.50-60 \mathrm{eV}\right)$ electrons. Their measured intenslty of $2.8 \pm 1 k R$ (Shemansky, et al., 1980) Implies a flux of $0.3 \mathrm{ergs} \mathrm{cm}^{-2} \mathrm{~s}^{-1}$. If this energy is deposited quite high in the atmosphere $1 t$ can be of potential value for heating the atmospheric gas. For Lyman and Werner bands to be detected outside the atmosphere by remote sensing, they must originate above the layer where methane begins to absorb (in $\lambda>1000 \AA$ ). The total energy needed to produce these bands is not quite sufficlent for the required amount of heating, and it is difficult to imagine precipitation of electrons in the equatorlal region - for which the data are presented in Fig. 4. Another difficulty with relating the heating to the presence of the $\mathrm{H}_{2}$-bands is that these emissions are nonexistent ( $\angle 500 \mathrm{R}$ ) on the nightside, Implying a highly asymetric electron energy spectrum. An upper limit of 0.04 ergs $\mathrm{cm}^{-2} \mathrm{~s}^{-1}$ at night set by this result is consistent with the excitation of H Lya at night (McConnell, et al., 1980a). Photoelectrons are found not to be responsible for either the $\mathrm{H}_{2}$-emissions or the heating.

The Voyager UVS detection of aurorae in the high latitude region mapped by the Ioplasma torus (Broadfoot, et al., 1979, 1980; Sande1, et a1., 1979) provides another potential source of heating. The measured Lya intensity in the auroral band was $60 \mathrm{kR}$, while the $\mathrm{H}_{2}$-Lyman and Werner band intensity was $80 \mathrm{kR}$, implying energy deposition of $1.3 \times 10^{13}$ watts. If this energy were allowed to be spread evenly over the entire disc of the planet, it would amount to $0.2 \mathrm{erg} \mathrm{cm}^{-2} \mathrm{~s}^{-1}$. The energy available is not sufficient for the required heating, even if pole to equator circulation were very efficient. There is no reason to expect it to be efficient. Futhermore, the range of high energy auroral electrons in an $\mathrm{H}_{2}$-atmosphere is large so that most of the heating produced by these electrons will take place quite deep in the atmosphere. There is evidence from the Voyager 2 entry occultation ionospheric measurement (Eshleman, et al., 1979b) that large amounts of energy must be deposited in the auroral region to cause excessive low altitude heating (see Sec. 5 on Ionosphere). It should be remarked that protons and other heavier ions such as sulfur and oxygen from the Io-plasma torus will have shorter range in the atmosphere than electrons with comparable energles. Consequently, heavier Ions would deposit their energy high in the atmosphere if there is a way for them to prectpitate in the Jovian ionosphere. Their densities, and the atmospheric density where they would dissipate their energy, are quite low.

Finally, one can Imagine that the drag between fons and neutralscould be as important on Jupiter as 1 it is on the Earth. For Joule heating to be important, heating should occur primarily in the ionization layers resembling terrestrial sporadic E revealed by Pioneer 10 and 11 radio occultation observations. 
Differential winds on the order of $200-300 \mathrm{~ms}^{-1}$ at density levels of $10^{12}$ to $10^{14}$ molecules $\mathrm{cm}^{-3}$ would be required to produce the heating. If the Joule heat ing takes place in the main lonosphere differential winds almost as strong are needed throughout the mesosphere, and the temperature gradient turns out to be too large. Whether such conditions exist is unknown. No information about thermospheric dynamics is currently available, and is not likely to become available from information obtained by the Galileo orbiter-probe experiments.

In summary, the mechan1sms so far suggested for heating of the thermosphere all have problems and lack a firm theoretical or observational basts. Much further analysis is needed before a credible candidate emerges.

\section{COMPOSITION}

The mean thermal velocity of the hydrogen atoms in Jupiter's upper atmosphere is about $5 \%$ of the escape velocity. Thus, it is unlikely even for the 11ghtest of planetary gases to have escaped from Jupiter. This view led to the consensus that the bulk composition of Jupiter's atmosphere should be close to that of the primordial nebula from which the sun and planets were formed. Ground based observations in the visible and Infrared more or less confirm the expected solar composition ratio of elements on Jupiter. Before the Voyager observations, the upper atmospheric distribution of gases was deduced theoretically by considering the photolysis of the gases, assuming that their bulk abundances were known. An overview of the earlier photochemical calculations for ammonia and methane, and the present understanding of their distributions is presented below.

Ammonia photochemistry has been studied in detall by Strobel (1973) and Atreya,

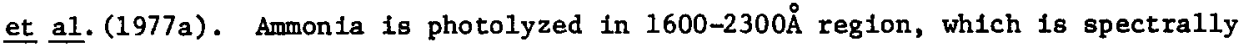
isolated from the region where methane absorbs UV. Because of its low vapor pressure in the Jovian troposphere, ammonia freezes out well below the region of methane photolysis. Thus, the methane and ammonia systems can be considered entirely separate from each other. The photochemical scheme of ammonia is shown in Figure 5. The abundance of the terminal product nitrogen, $N_{2}$, is highly dependent on the degree of supersaturation of $\mathrm{NH}_{3}$, and the intermediate product hydrazine, $\mathrm{N}_{2} \mathrm{H}_{4}$. Atreya, et al. (1977a) calculated the range of values possible for the $\mathrm{N}_{2}$ mixing ratio, depending upon whether or not $\mathrm{N}_{2} \mathrm{H}_{4}$ was supersaturated. Barker, et al. (1980) have recently attempted to detect the $\mathrm{N}_{2}{ }^{+}$flrst negative band system at $3914 \AA$ and $4278 \AA$ in the auroral region of Saturn, and found an upper limit of 1 to $2 \mathrm{kR}$. However, photolysis of ammonia should produce much more $\mathrm{N}_{2}$ on Jup 1ter than on Saturn. Thus, it is not unlikely that large amounts of nitrogen may be present on Jupiter. Although $\mathrm{N}_{2}$ is the terminal product in the photochemical scheme of Fig. 4, 1ts density in the atmosphere is limited. It will be mixed downward and deep in the Jovian Interior be recycled to ammonia by the termolecular reaction, $\mathrm{N}_{2}+3 \mathrm{H}_{2} \rightarrow \mathrm{NH}_{3}$. Current estimates (Sato and Hansen, 1979) indicate 1 to 1.5 times the solar ratio for $\mathrm{N} / \mathrm{H}$ on Jupiter. The Voyager IRIS observations of the pure rotational bands at 50um and $v_{2}$ vibrational-rotation band at $10 \mu \mathrm{m}$ indicate that the $\mathrm{NH}_{3} \mathrm{mlxing}$ rat lo is lower than the saturated value in the upper troposphere ( $R$. Hanel, and D. Gautier, personal communtcation, 1980). 


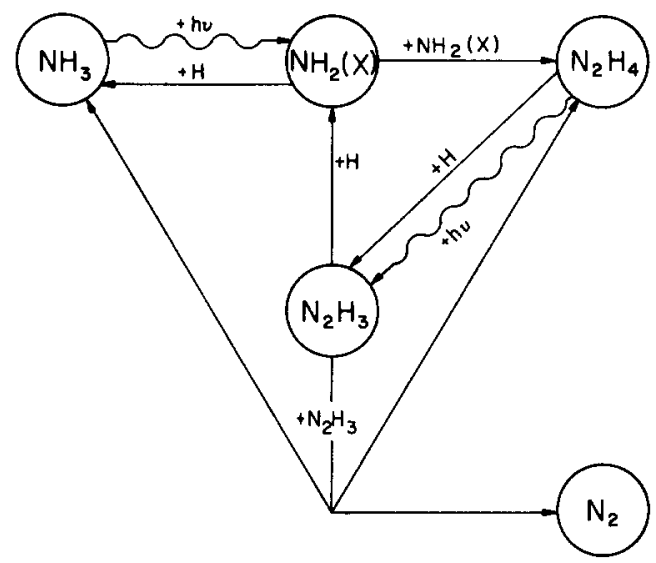

F1g. 5. Photochemistry of ammonia in the Jovian atmosphere (Atreya, et al., 1978).

Their results shown in Fig. 6 indicate $N_{2}$ mixing ratios between $10^{-8}$ and $3 \times 10^{-11}$ at the cloud tops $\left(0.6\right.$ bar). Detection of $\mathrm{N}_{2}$ on Jupiter has not yet been reported.

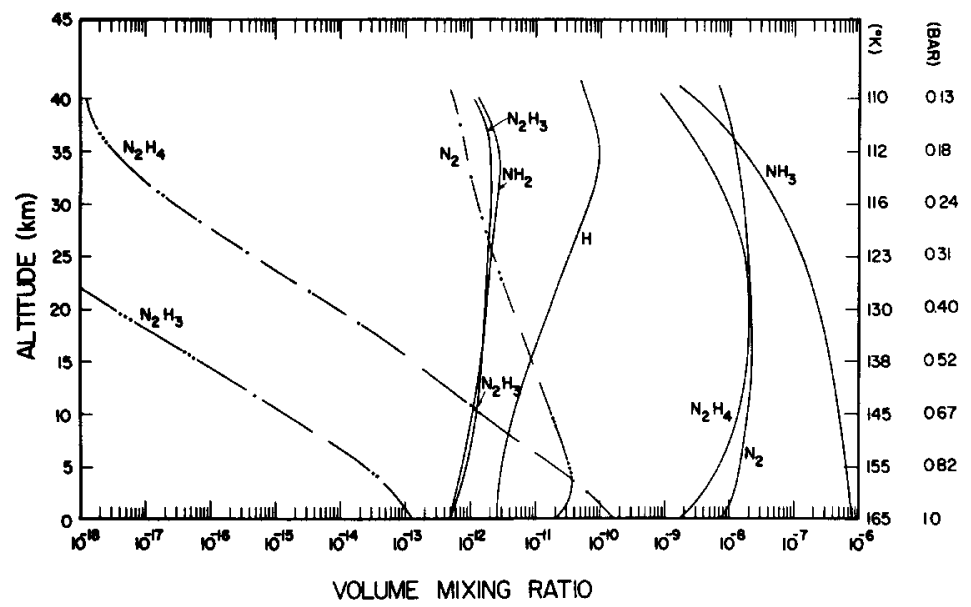

Fig. 6. Volume mixing ratios of ammonia and its photochemical products for Hunten (1976) temperature prof $11 \mathrm{e}$ and the $\mathrm{K} \propto 1 / \mathrm{M}^{1 / 2}$ atmospheric model (solid line curves). The temperatures and pressures given on the right ordinate correspond to the altitudes shown on the left (Atreya, et al., 1977a). Curves 11lustrated by - . . for $\mathrm{N}_{2} \mathrm{H}_{4}$ and $\mathrm{N}_{2} \mathrm{H}_{3}$ assume a saturation vapor mixing ratio. The resultant $\mathrm{N}_{2}$ mixing ratio profile is shown by the - . - - curve. The ammonia cloud tops are at a pressure level of about 0.6 bar.

Next, we turn to the aeronomy of methane. The photolysis of methane shortward of $1600 \AA$ results in the production of heavier hydrocarbons, acetylene $\left(\mathrm{C}_{2} \mathrm{H}_{2}\right)$, ethane $\left(\mathrm{C}_{2} \mathrm{H}_{6}\right)$ and ethylene $\left(\mathrm{C}_{2} \mathrm{H}_{4}\right)$, along with numerous intermediate radicals. The photochemical scheme is shown in Fig. 7. One dimensional continuity and transport calculations carried out by Strobel (1975) yield the height distribution of the products. The calculations by Strobel need drastic revision in view of the fact that photoabsorption cross sections of methane and ethane have been substantially revised. Mount, et al. (1977) find that the methane photoabsorption cross sec- 
tions In the wavelength region $\lambda>1475 \AA$ are a factor of 200 lower than the values used by Strobel. Mount and Moos (1978) find that at 200K their measurements of ethane photoabsorption cross sections yield values wh1ch are $20 \%$ lower than the Okabe and Becker (1963) values used by Strobel (1975). Moreover, several key

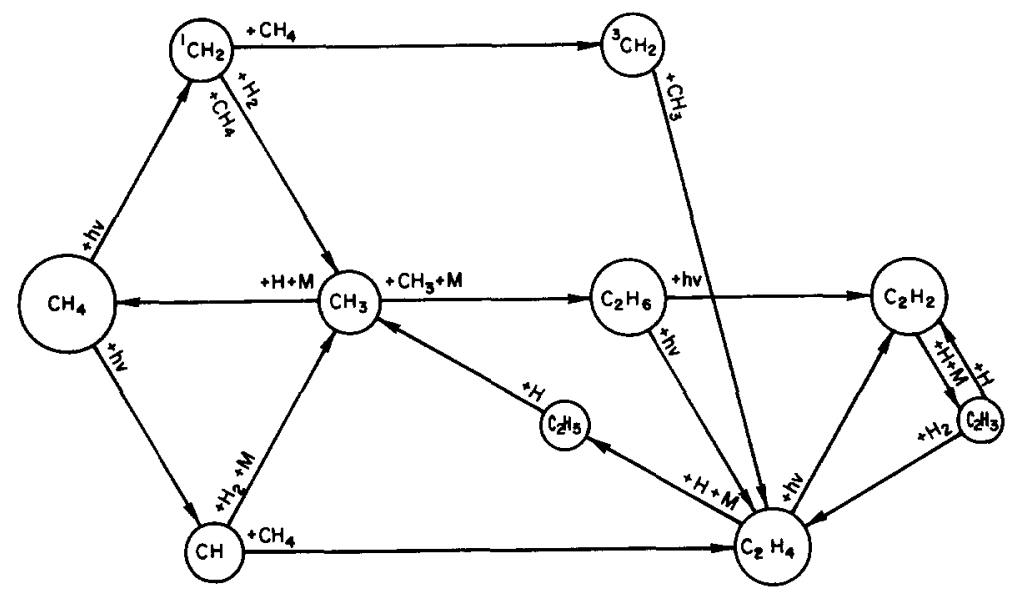

Fig. 7. Photochemistry of methane in the Jovian atmosphere (strobe1, 1975).

reaction rates in the chemical scheme have been revised and are 11sted by Yung and Strobel (1980). The value of the eddy diffusion coefficient at the homopause at the time of the Voyager observations is different than that used by Strobel. In view of these changes and the results of the Voyager $\alpha$ Leo stellar occultation measurements, it is approprlate to show only the hydrocarbon density profiles as we know them now. Unlike the solar occultation experiment, the stellar occultation data are not averaged over large height intervals. The height resolution in the latter is limited by the rate of descent of the minimum tangent ray altitude in the atmosphere. The $\alpha$ Leo stellar occultation experiment (Festou, et al., 1980) resulted in an effective height resolution of about $15 \mathrm{~km}$ which is about one half of the atmospheric scale height at $1 \mathrm{mb}$. Although theoretically it is possible to achieve $3.2 \mathrm{~km}$ height resolution, some integration of the data was necessary to improve the statistics. The analysis of Festou, et al., yields $\left[\mathrm{CH}_{4}\right] /\left[\mathrm{H}_{2}\right]=2.5$ $\times 10^{-5},\left[\mathrm{C}_{2} \mathrm{H}_{6}\right] /\left[\mathrm{H}_{2}\right]=2.5 \times 10^{-6}-$ both at $5 \mu \mathrm{b}$, and $\left[\mathrm{C}_{2} \mathrm{H}_{2}\right] /\left[\mathrm{H}_{2}\right] \leqslant 5 \times 10^{-6}$ at $10 \mu \mathrm{b}$ level. The $\mathrm{CH}_{4} / \mathrm{H}_{2}$ mixing ratio deduced from the infrared data in the two wings of the $v_{4}$ band of $\mathrm{CH}_{4}$ was found to be $(1.4 \pm 0.45) \times 10^{-3}$, which is $1.5 \pm 0.5$ times that for the solar ratio of elements. The preliminary analysis of the IRIS observations gives $\mathrm{C}_{2} \mathrm{H}_{2} / \mathrm{H}_{2}=3 \times 10^{-8}$ to $10^{-7}, \mathrm{C}_{2} \mathrm{H}_{6} / \mathrm{H}_{2}=5 \times 10^{-6}$ deep in the atmosphere (10100mbar level) and show latitudinal variations (Hanel, et al., 1979; and R. Hanel, personal communication, 1980). Substantially different mixing ratios are expected higher in the atmosphere due to photochemical transformation. The IRIS data are being analyzed further ( $R$. Hanel, 1980, personal communication) to determine hydrocarbon mixing ratios in a region which would overlap the UVS data.

The measured densities of $\mathrm{H}_{2}, \mathrm{CH}_{4}, \mathrm{C}_{2} \mathrm{H}_{6}$, and $\mathrm{C}_{2} \mathrm{H}_{2}$ are shown as a function of height in Fig. 8. No $\mathrm{C}_{2} \mathrm{H}_{4}$ has been found at $10 \mu \mathrm{b}$ level. The He density in the figure is simply a representation of the He mixing ratio measurement by IRIS in the homosphere. Conspicuouslyabsent from this figure is a distribution of atomic 
hydrogen. If ultraviolet absorption were the only source of atomic hydrogen, it would be produced primarily by dissoclative photolonization and photodissociation of $\mathrm{H}_{2}$. Subsequently, $\mathrm{H}$ would be transported in the deep atmosphere where it would be removed by a three body recombination reaction $\left(\mathrm{H}+\mathrm{H}+\mathrm{M} \rightarrow \mathrm{H}_{2}+\mathrm{M}\right)$. Photolysis of

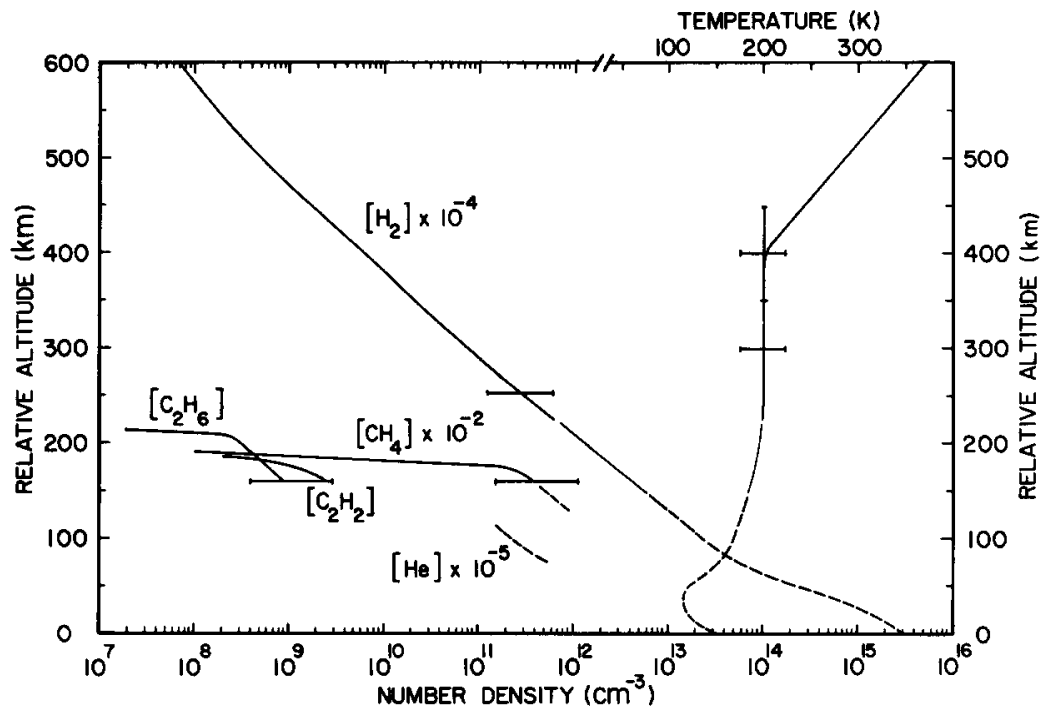

Fig. 8. $\mathrm{H}_{2}, \mathrm{CH}_{4}, \mathrm{C}_{2} \mathrm{H}_{6}$ and $\mathrm{C}_{2} \mathrm{H}_{2}$ density profiles deduced from the $\alpha$ Leo stellar occultation data. The helium mixing ratio is measured to be $0.10 \pm 0.03$ by IRIS. The thermal structure shown in this figure is the same as in Fig. 4. Altitudes are measured from the ammonia cloud tops $(P=600 \mathrm{mb}, T=150 \mathrm{~K})$ and corresponding pressures are shown on the right ordinate. Readers wishing to use this figure must consult Atreya, et a1. (1980), and Festou, et a1. (1980).

methane and ammonia would contribute to the atomic hydrogen abundance source. The above sources of atomic hydrogen are suffictent to explain the $0.4 \mathrm{kR}$ of Lyo measured by the Ploneer 10 photometer, If resonance scattering of the solar Lya photons 18 responsible for the excitation. The Voyager UVS observed more than thirty times as much Jovian Lya. This increase cannot be explained by a factor of 2.5 Increase in the solar Lyman alpha flux that occurred between 1973 and 1979 . The excess hydrogen must be provided by means other than the photodissociation of $\mathrm{H}_{2}$. Particle precipitation can provide the extra source. Thus, one cannot confidently model the production of atomic hydrogen at this time. The Ly $\alpha$ observations yield an average column abundance of $1 \times 10^{17} \mathrm{~cm}^{-2}$ (McConnell, et al., 1980a) for atomic hydrogen above the layer where the optical depth of methane at Lya is one. This abundance increases to $3 \times 1.0^{17} \mathrm{~cm}^{-2}$ in the region of enhanced Lya emission, indicating longitudinal asymmetry (Sandel, et al., 1980; Dessler, et al., 1980).

\section{EDDY DIFFUSION COEFFICIENT}

Many problems of planetary aeronomy require an understanding of the mixing processes in the stratosphere and mesosphere which can be mathematically represented by a parameter - the eddy diffusion coefficient, $k_{h}$. Information concerning $\mathrm{K}_{h}$ in the Jovian atmosphere was limited to that inferred from the measurement of the Lyo albedo of the planet, until the Voyager UVS observations of the hydrocarbon density profiles provided a more direct means of determining the 
level of the homopause. By definition the value of the eddy diffusion coefficient is equal to the molecular diffusion coefficient at the homopause.

According to a hypothesis developed by Hunten (1969) and Wallace and Hunten (1973), the homopause value of the eddy diffusion coefficient can be related to the column abundance of atomic hydrogen $\mathrm{N}_{\mathrm{H}}$ above the methane absorption level (generally the homopause) by an inverse functional relationship. On the other hand, the atomic hydrogen column abundance varies as the square of the Lyo albedo. It is assumed that resonance scattering of the solar Lyman alpha photons is the only mechanism that excited Lyo emission from Jupiter, and the exospheric temperature is low $(-150 \mathrm{~K})$. The concept is relatively straightforward: large $\mathrm{K}_{\mathrm{h}}$ (1.e, higher homopause level) permits smaller $\mathrm{N}_{\mathrm{H}}$ above the homopause resulting in smaller scattered Lya, and vice-versa. Based on the above hypothesis we have calculated $\mathrm{K}_{\mathrm{h}}$ for all the Lyo observations of Jup1ter (Table 1). The highest value, $\mathrm{K}_{\mathrm{h}} \approx 10^{8} \mathrm{~cm}^{2} \mathrm{~s}^{-1}$, corresponds to a Ly $\alpha$ intensity of $0.4 \mathrm{kR}$, while the lowest value of $K_{h} \approx 5 \times 10^{5}$, corresponds to the highest measured Lya intenstty of 14kR. Actually, the Voyager UVS detected Lyo intensities as high as $20 \mathrm{kR}$ at selected longitudes in the equatorial region. The median value of $\mathrm{k}_{\mathrm{h}}$ between $10^{6}$ and $10^{7}$ is calculated for the times of medium Jovian Lyo intensity - about 2 to $4 \mathrm{kR}$ as measured by the Copernicus $0 \mathrm{AO}-3$ satellite.

The deduction of $\mathrm{K}_{h}$ based on the Lya intensity in the manner described above is not appropriate if excitation by means other than solar resonance scattering occurs and if the exosphere is hot. The uvs observed a lyo nightglow with an emission rate of $1 \mathrm{kR}$, presumably caused by particle excitation. This feature may well be present on the dayside also. Moreover, particle precipitation provides a source of atomic hydrogen in addition to the dissoctative photoionization and photodissociation of $\mathrm{H}_{2}$, and photolysis of $\mathrm{CH}_{4}$ and $\mathrm{NH}_{3}$. Charged particle destruction of methane can lead to a rapid decrease in the $\mathrm{CH}_{4}$ density well below the homopause. The Wallace and Hunten calculations need to be revised also in view of the fact that the upper atmosphere is hot with a temperature nearly a factor of ten greater than assumed in the above calculations. Until they are repeated the calculations of Wallace and Hunten yield an order of magnitude estimate of the value of the eddy diffusion coefficient.

The Voyager ultraviolet stellar occultation experiment gives measurements of equatorial $\mathrm{CH}_{4}$ and $\mathrm{C}_{2} \mathrm{H}_{2}$ densities as a function of height (Fig. 8). It is quite unlikely that particle destruction of $\mathrm{CH}_{4}$ would take place in the equatorial regions. Atreya, et al. (1980) therefore, constructed several models of the methane photolysis with eddy diffusion coefficient and its variation with altitude as a free parameter. (These calculations took into consideration all the improvements in the $\mathrm{CH}_{4}$ photochemistry described in Sec. 3). The best fit to the data was obtained with $\mathrm{K}_{\mathrm{h}}=1.4_{-0.7}^{+0.8} \times 10^{6} \mathrm{~cm}^{2} \mathrm{~s}^{-1}$. The range of values in $\mathrm{K}_{h}$ is a reflection of the statistical uncertainty in the data and the precision with which the level at which the hydrocarbon densities fall off can be fixed. The above value of $k_{h}$ is to be compared with that deduced from the Voyager Ly $\alpha$ observations, i.e., $-10^{6} \mathrm{~cm}^{2} \mathrm{~s}^{-1}$. 
TABLE 1

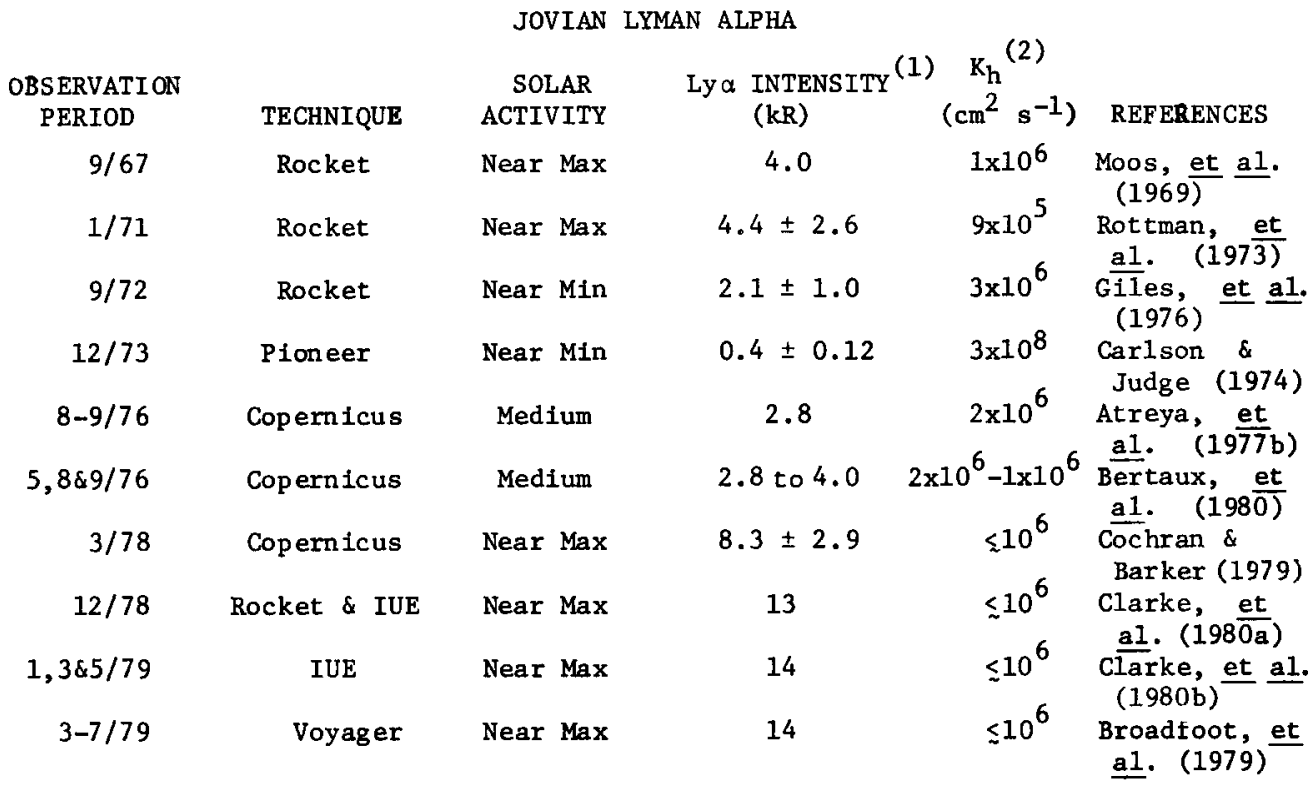

${ }^{1}$ Copernicus intensities have been adjusted for the new geocoronal calibration factor of Bertaux, et al. (1980).

2 Eddy diffusion coefficient at the central value of Lya intensity using Wallace and Hunten (1973) calculations. See text for discussion of $K_{h}$.

The presence of helium in the upper atmosphere of Jupiter is revealed by the detection of He $584 \AA$ emission in the dayglow spectrum (McConnel1, et al., 1980b). If this spectral feature is produced in resonance scattering of solar $584 \AA$ radiation its apparent emission rate depends on the flux at the center of the solar $584 \AA$ Iine (total flux and line width), the mixing ratfo of He below the homopause or the He to $\mathrm{H}_{2}$ ratio, the value of the eddy diffusion coefficient at the homopause, $K_{h}$, and the effective temperature in the scattering region. As in the case of hydrogen, the smaller the values of $\mathrm{K}_{h}$ the larger is the column He to $\mathrm{H}_{2}$ ratio. The higher the temperature in the region of effective scattering, the greater is the line width and the more effective a given amount of helium is in scattering. Hence, smaller hellum column densities and larger values of $\mathrm{K}_{h}$ are needed to produce a given airglow brightness. The $584 \AA$ dayglow observed by Voyagers 1 and 2 were 5.5 $\mathrm{R}+30 \%$ and $3.9 \mathrm{R} \pm 20 \%$, respectively. Assuming a He to $\mathrm{H}_{2}$ ratio of $0.10 \pm 0.3 \mathrm{~V} / \mathrm{V}$ as determined by the IRIS experiment, implies a value of $\mathrm{K}_{\mathrm{h}}$ of about $8 \times 10^{5} \mathrm{~cm}^{2} \mathrm{~s}^{-1}$ if the temperature in the scattering region is $150 \mathrm{~K}$, and a value of $\mathrm{K}_{\mathrm{h}}$ of about $2 \times 10^{7}$ $\mathrm{cm}^{2} \mathrm{~s}^{-1}$ if the temperature is $1000 \mathrm{~K}$. The former combination is consistent with the assumption that all of the dayglow Ly $\alpha$ is produced by resonance scattering $\mathrm{N}_{\mathrm{H}}$ of about $10^{17} \mathrm{~cm}^{-2}$ (McConnell, et al., 1980a). In fact, the temperature at which most of the resonance scattering by He occurs is neither $150 \mathrm{~K}$ nor $1000 \mathrm{~K}$. With the altitude of this region lying at around $400 \mathrm{~km}$ the temperature according to Fig. 4 will probably be on the order of 200k. Hence, the value of $k_{h}$ that would appear to follow from the He airglow analysis $1 \mathrm{~s}$ closer to $10^{6} \mathrm{~cm}^{2} \mathrm{~s}^{-1}$, which is consistent with that deduced from the stellar occultation observations. of course, it should be noted that the airglow value is averaged over the daytime 
hemisphere, while the occultation value refers to the tropics. The Ploneer 10 observation of $5.1 R$ of $584 \AA$ airglow in 1973 (when the effective solar radiation was only about one-fourth as strong as in 1979), would imply values of $k_{h}$ in the range $3 \times 10^{7}-10^{9} \mathrm{~cm}^{2} \mathrm{~s}^{-1}$, consistent with the conclusions forced by the low Lya dayglow values also reported.

\section{IONOSPHERE}

Radio occultation experiments have provided several measurements of the Jovian ionosphere as listed in Table 2.

\section{TABLE 2}

PIONEER AND VOYAGER IONOSPHERIC MEASUREMENTS

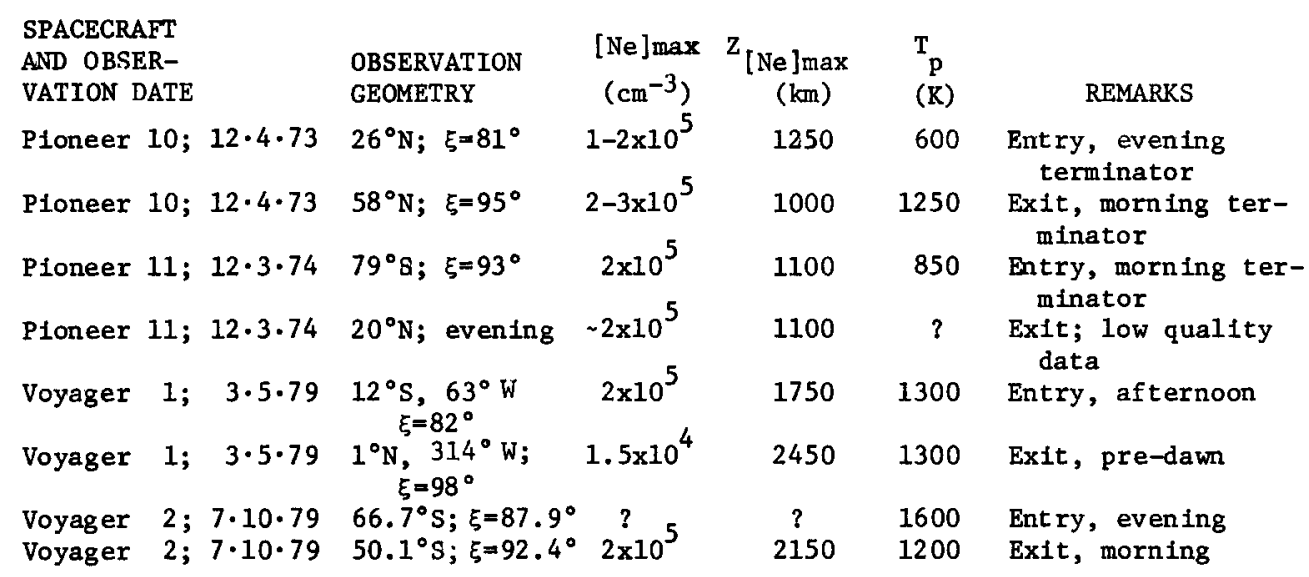

$\mathrm{Z}_{\text {[Ne]max }}$ is the altitude of the electron density maximum, [Ne]max, above the ammonia cloud tops; $T_{p}=$ topside plasma temperature; $\xi$ is solar zenith angle.

Figures 9, 10, 11 and 12 show lonospheric profiles measured on Pioneer 10 and 11 and Voyager 1 and 2 . One notes in the Pfoneer data considerable diurnal, temporal, latitudinal and longitudinal variations in the peak electron density, plasma scale height, extent of the ionosphere and number of lonospheric layers. In general, however, the Ploneer data indicate a peak electron density of (1-2) $\times 10^{5} \mathrm{~cm}^{-3}$ at an altitude of $1000 \mathrm{~km}$ and six to seven Ionization layers above and below the peak; the plasma scale height corresponds to a temperature $\sim 850 \mathrm{~K}$ in the topside 1onosphere (Fjeldbo, et al., 1975, 1976). There is no clear indication of a diurnal variation in the peak electron density. The Voyager 1 equatorial data, on the other hand, show a factor of 10 decrease in the peak electron density from day to night; the topside scale height corresponds to a temperature on the order of 1200-1300K (Eshleman, et al., 1979a). The high latitude lonosphere measured on Voyager 2 is not at all typical. The Voyager 2 entry data correspond to the region where the Io-plasma torus is magnetically mapped on to Juplter, and consequently, a large amount of energy is precipitated in this region, leading to a relatively hot plasma - as is indicated by the large scale helght. 


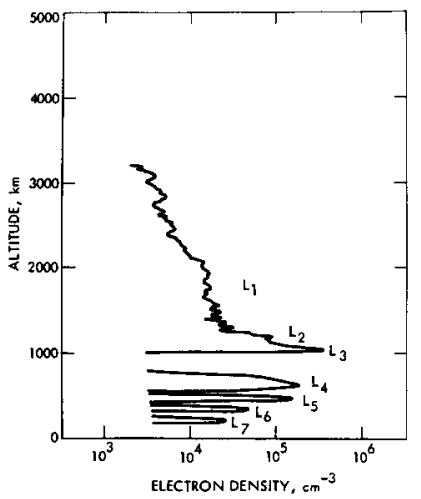

Fig. 9. Ploneer 10 radio occultation measurement of the electron density profile for early morning conditions: solar zentth angle $95^{\circ}$, latitude $58^{\circ} \mathrm{N}$; topside plasma scale helght $\sim 800 \mathrm{~km}$ (Fjeldbo, et al., 1975). The zero of the scale is at atmospheric density level of $3 \times 10^{18}$ molecules $\mathrm{cm}^{-3}$, which is about $50 \mathrm{~km}$ above the ammonia cloud tops.

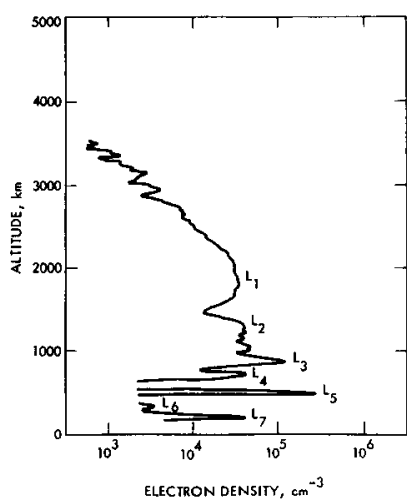

F1g. 10. Pioneer 10 radio occultation measurement of the electron density profile for late afternoon conditions: solar zenith angle $81^{\circ}$, latitude $26^{\circ} \mathrm{N}$; topside plasma scale height $\sim 375 \mathrm{~km}$ (Fjeldbo, et al., (1975). Height scale is the same as in Fig. 9.

The sources of ionization on Jupiter can be classifled into two categories - the solar euv, and the particle precipitation. Early lonospheric models were calculated by McElroy (1973). Numerous chemical reactions in addition to those listed by McElroy were recognized to be important by Atreya, et al. (1974), and Atreya and Donahue (1976). The ionospheric chemical scheme shown in Fig. 13 is a composite of the table of reactions from Atreya and Donahue (1976) and a potentla11y important reaction involving charge exchange of $\mathrm{H}^{+}$with vibrationally excited $\mathrm{H}_{2}$. The primary source of ionization is solar euv which is absorbed continuously by $\mathrm{H}_{2}$ below $912 \AA$, by $\mathrm{H}$ below $911 \AA$ and by He below $504 \AA$. Subsequent to lonization, ton-atom/molecular interchange results in numerous intermediate and terminal fons as shown in Fig. 13. The major Ion in the topside fonosphere, i.e., above the electron density maximum tums out to be $\mathrm{H}^{+}$. Below the maximum, $\mathrm{H}_{3}^{+}$and hydrocarbon ions $\mathrm{CH}_{5}{ }^{+}$and $\mathrm{C}_{2} \mathrm{H}_{5}{ }^{+}$dominate. The terminal fons throughout the ionosphere are shown by shaded circles in Fig. 13; these ions are removed by electron recom- 


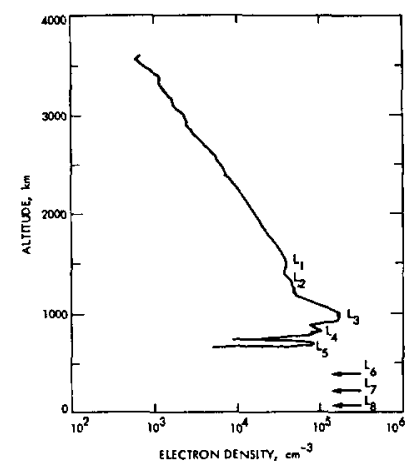

Fig. 11. Pioneer 11 radio occultation measurement of the electron density profile for early morning conditions: solar zenith angle $93^{\circ}$, latitude $79^{\circ} \mathrm{S}$; topside plasma scale helght $\sim 540 \pm 60 \mathrm{~km}$ (Fjeldbo, et al., 1976). The altitude reference is at an atmospheric density level of $2 \times 1017$ molecules $\mathrm{cm}^{-3}$, which is about 100km above the ammonia cloud tops.

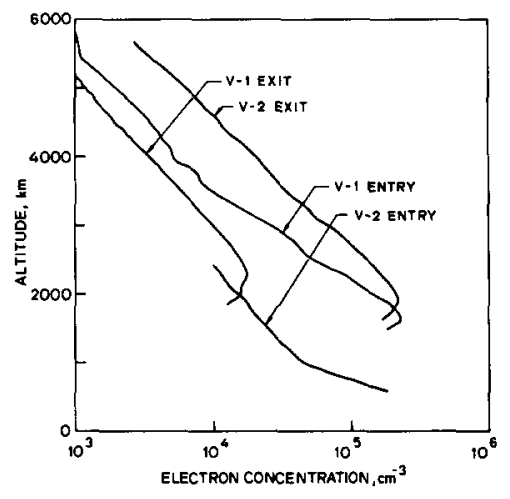

Fig. 12. Voyager 1 and 2 RSS data on the electron density profiles (Eshleman, et al., $1979 \mathrm{a}, \mathrm{b}$; and the RSS group). Voyager 1 entry occultation occurred in late afternoon at $12^{\circ} \mathrm{S}, 63^{\circ} \mathrm{W}$; solar zenith angle $82^{\circ}$. The Voyager 1 exit occultation took place in pre-dawn at $11^{\circ} \mathrm{N}, 314^{\circ} \mathrm{W}$; solar zentth angle $98^{\circ}$. The Voyager 2 entry occultation geometry is $66.7^{\circ} \mathrm{S}$, solar zenith angle $87.9^{\circ}$, evening conditions; exit at $50.1^{\circ} \mathrm{S}$, solar zenith angle $92.4^{\circ}$, morning conditions. The Voyager 2 entry data represent dayside conditions in the invariant latitude range where the Io-plasma torus magnetically mapped on Jupiter. The helght reference is at $1 \mathrm{mb}$ level, approximately $160 \mathrm{~km}$ above the ammonia cloud tops.

bination. The fate of the less important lower altitude hydrocarbon lons is not known precisely; they could get converted to heavier hydrocarbon ions such as $\mathrm{C}_{3} \mathrm{H}_{8}{ }^{+}$or $\mathrm{C}_{4} \mathrm{H}_{9}{ }^{+}$. No rellable data on the rates for reactions involving such lons are available.

Based on the chemical scheme just described, and using a model of the atmosphere which assumed an eddy diffusion coeffictent at the homopause of $-3 \times 10^{7} \mathrm{~cm}^{2} \mathrm{~s}^{-1}$, Atreya and Donahue (1976) calculated an lonospheric profile to theoretically explain the Ploneer 10 dayside lonosphere in the equatorlal region $\left(26^{\circ} \mathrm{N}, \xi=81^{\circ}\right.$; Fig. 10) radto occultation measurements. Figure 14 shows that the attempt was quite successful in explaining the main lonospheric feature when transport of the ions was taken into consideration. The location of the layer $L_{7}$ appears to 


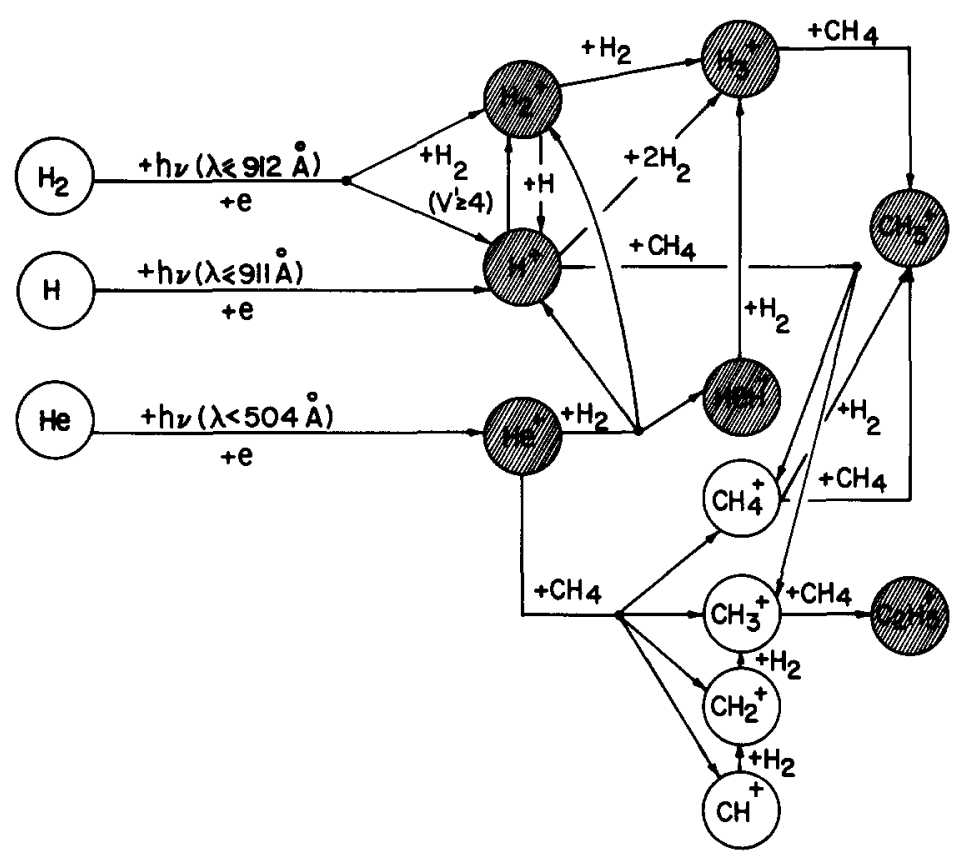

Fig. 13. Significant chemical reactions in the Jovian ionosphere.

coincide with a maximum in the $\mathrm{CH}_{3}{ }^{+}$ion production rate - which shows up as a shoulder at about $200 \mathrm{~km}$ in the calculation ( $F$ ig. 10). The current measurements of the hydrocarbon profiles (Voyager data, Festou, et al., 1980), however, would tend to make this shoulder disappear. In their pre-Ploneer model, Atreya, et al. (1974) suggested the possibility that Na atoms then known to exist near Io (Brown, 1974) could be ionized (by electron impact or photons) and removed along the magnetic field lines to the Jovian fonosphere. There they could result in sporadic $\mathbf{E}$ type layering. Long lived metallic ions concentrated by wind shear electric fields are known to form layers in the terrestrial lonosphere. The source of the metallic ions could be meteoritic in origin as well. The Voyager observations have shown the presence of Ions of sulfur and oxygen in the Ioplasma torus. No observations exist to confirm the migration of the heavy ions to the Jovian ionosphere, but thelikelihood is great. It is important to recognize that no measurements of the 'height profiles' of temperature or important gases, (such as $\mathrm{CH}_{4}, \mathrm{C}_{2} \mathrm{H}_{2}, \mathrm{C}_{2} \mathrm{H}_{6}$ and $\mathrm{H}_{2}$ ) in the mesosphere and thermosphere were made unt 11 Voyager observations. The ionospheric calculations for the Pioneer 10 epoch are, therefore, necessarily based on theoretical models of the above parameters - as best as they could be modeled at that time. Although Voyager data would modify these models, there seems to be no systematic way of scaling the data from the Voyager to the Ploneer epoch.

When the measured profiles of the atmospheric gases, and the temperature (Fig. 8) (Festou, et al., 1980), and the chemical scheme shown In Fig. 13 are used to model the ionosphere at the time of the Voyager 1 encounter, it is found that the results are less satisfactory (Fig. 15) than indicated In Fig. 14. The measured peak electron density is apparently lower than the calculated one, and the altitude of 


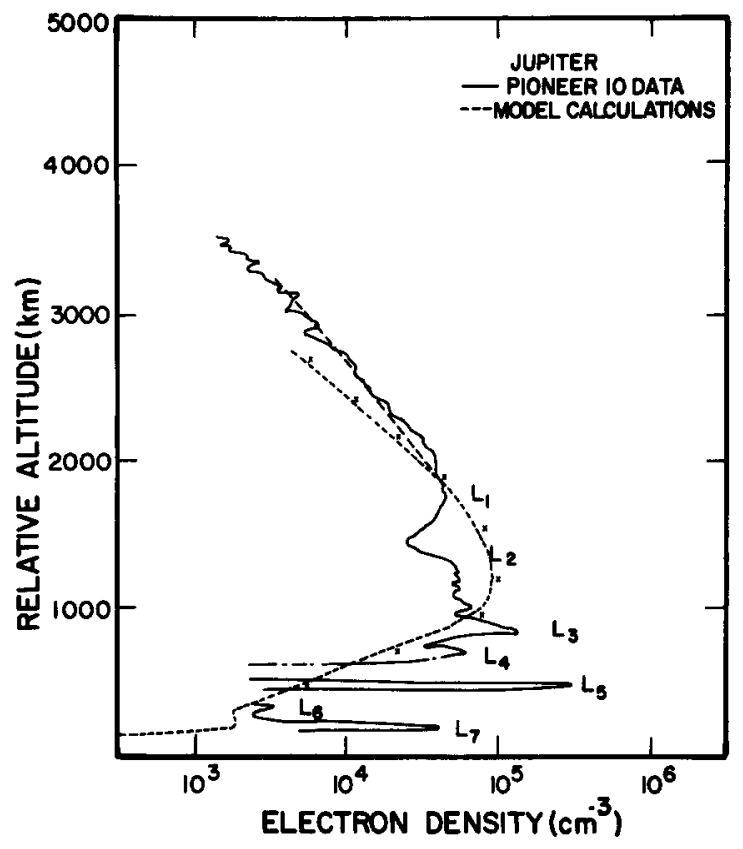

Fig. 14. Comparison of electron density profile measured by the Pioneer 10 radio occultation experiment (FIg. 10) and model calculations assuming a $1000 \mathrm{~K}$ exospheric temperature. The short-dashed curve assumes a $T-0.5$ vartation for radiative recombination rate, $\alpha_{r}$ of $\mathrm{H}^{+}$and $\mathrm{He}^{+}$. Joining of $\mathrm{X}^{\prime} \mathrm{s}$ will yleld the profile when $\alpha_{r} \propto \mathrm{T}-0.75$. The long-dashed curve shows the distribution under the assumptions of diffusive equilibrium, and $\alpha_{\mathrm{r}}<\mathrm{T} \mathrm{e}^{-0.5}$. The main ion is $\mathrm{H}^{+}$, except that the secondary peak at the location of layer $\mathrm{L} 7$ is where production of $\mathrm{CH}_{3}^{+}$ peaks. The height scale is same as in Fig. 10. Atreya and Donahue (1976).

the measured peak higher. There are several ways to explain this. One possibility is that the observed peak is not the ionization maxmimum but merely a high layer. Indeed, this is the case with the Ploneer data - layers overlie a smoother profile and it is difficult to say where the maximum in the electron density would be if there were no layers.

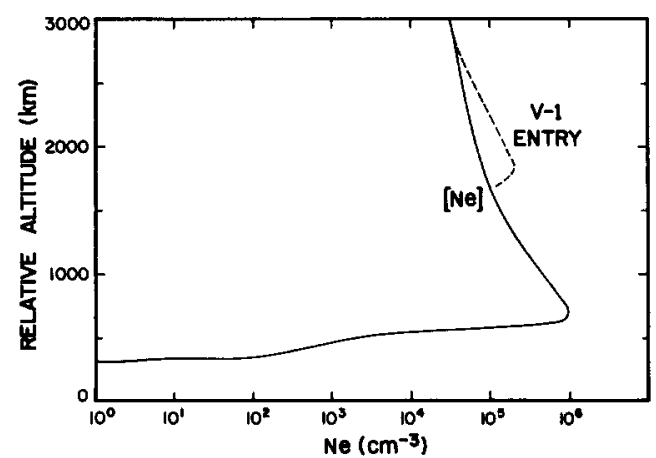

Fig. 15. Electron density calculated using photochemical scheme shown in F1g. 13 and for the geometry of observation corresponding to the Voyager 1 entry occultat1on (F1g. 12). The distribution of gases and temperature in the atmosphere is taken from Fig. 8. 
If the maximum is as high as indicated by the data it would be necessary to Invoke a mechanism to raise the altitude of the peak. Small vertical drifts on the order of 1 to $2 \mathrm{~ms}^{-1}$ are adequate, and can be supplied by a slow meridional wind system. It is obvious that further constderation is needed before a satisfactory fit to the data can be obtained. It should be noted that ionization by charged particles cannot play an important role in the equatorial region for which the Voyager 1 Ionospheric measurements have been carried out. Layers do appear to exist in the Voyager epoch Lonosphere, and their location and magnitude are currently being investigated (V. Eshleman, personal communication, 1980).

The diurnal variation in the peak electron density appears to be due to the converston of the major Ion, $\mathrm{H}^{+}$to the molecular ion $\mathrm{H}_{2}^{+}$, and subsequently, to $\mathrm{H}_{3}^{+}$ which has a much faster rate of electron recombination than $\mathrm{H}^{+}$. The sequence of the reactions is as follows:

$$
\begin{aligned}
\mathrm{H}^{+}+\mathrm{H}_{2}\left(\mathrm{v}^{\prime} \mathrm{ZH}^{4}\right) & \rightarrow \mathrm{H}_{2}^{+}+\mathrm{H} \\
\mathrm{H}_{2}^{+}+\mathrm{H}_{2} & \rightarrow \mathrm{H}_{3}^{+}+\mathrm{H} \\
\mathrm{H}_{3}^{+}+\mathrm{e} & \rightarrow \mathrm{H}_{2}+\mathrm{H}
\end{aligned}
$$

Atreya, et al. (1979b) found that the population of the vibrationally excited $\mathrm{H}_{2}$ may be large enough for the above sequence of reactions to be of importance when the exospheric temperature is greater than 1200K. Thus, at the time of the Pioneer observations when the exospheric temperature was $\sim 850 \mathrm{~K}$, no diurnal variation in the electron density was expected or found because the lifetime of $\mathrm{H}^{+}$in the cold fonosphere was much longer than one Jovian night. At the time of the Voyager equatorial observations, the exospheric temperature was high - on the order of $1450 \mathrm{~K}$ as has been noted, so that a sufficiently large population of $\mathrm{H}_{2}$ existed in high vibration levels to cause the mechanism of Atreya, et al. (1979b) to be effective. To explain a factor of 10 decrease in the electron density from day to night, an overall rate of $4 \times 10^{-16} \mathrm{~cm}^{3} \mathrm{~s}^{-1}$ for reaction (1) would be required. Gas kinetic considerations do not rule out such a value for this rate constant; however, laboratory measurements for it do not yet exist.

The high latitude nightside lonosphere looks much like the equatorial dayside ionosphere. One reason could be that the topside plasma temperature is lower (about 1200K) than in the equatorial observations, resulting in a lower population of the vibrationally excited $\mathrm{H}_{2}$ molecules. Thus, $\mathrm{H}^{+}$may not be converted to heavier lons. As stated earlier the Voyager 2 dayside ionosphere is in the region where the Io-plasma torus was magnetically mapped on Jupiter, and perhaps represents anomalous conditions. In all high latitude calculations, one should also keep in mind that particle precipitation may substantlally alter the characteristics of the electron density profile.

\section{SUMMARY}

Explanation of the high exospheric temperature of the Jovian atmosphere and its increase between 1973 and 1980 poses a sertous aeronomical problem. A source that deposits 0.5 ergs $\mathrm{cm}^{-2} \mathrm{~s}^{-1}$ at high altitude is required and none that is really satisfactory is so far suggested. The apparent large decrease in eddy coefficient at the homopause indicated by He 584, H Lya afrglow observations and fonospheric 
modelling also needs explanation. On the other hand, our understanding of ionospheric processes seems to be adequate. This state of affairs depends, however, on verification of a proposal that conversion of $\mathrm{H}^{+}$to $\mathrm{H}_{2}^{+}$by charge transfer of $\mathrm{H}^{+}$with vibrationally excited $\mathrm{H}_{2}$ has a large rate constant.

Acknowledgment

This research was supported by a grant from the NASA Planetary Atmospheres Program.

\section{REFERENCES}

Atreya, S. K., Donahue, T. M. and McElroy, M. B. (1974) Jupiter's ionosphere: prospects for Pioneer 10, Science, 184, 154-156.

Atreya, S. K. and Donahue, T. M. (1976) Model ionospheres of Jupiter; in: Jupiter (Gehrels, T., Ed.) pp. 304-318, University of Arizona Press.

Atreya, S. K., Donahue, T. M. and Kuhn, W. R. (1977a) The distribution of ammonia and its photochemical products on Jupiter, Icarus, 31, 348-355.

Atreya, S. K., Yung, Y. L., Donahue, T. M. and Barker, E. S. (1977b) Search for Jovian auroral hot spots, Astrophys. J., 218, L83-L87.

Atreya, S. K., Donahue, T. M. and Kuhn, W. R. (1978) Evolution of a nitrogen atmosphere on Titan, Science, 201, 611-613.

Atreya, S. K. and Donahue, T. M. (1979) Models of the Jovian upper atmosphere, Rev. Geophys. Space Phys., 17, 388-396.

Atreya, S. K., Donahue, T. M., Sande1, B. R., Broadfoot, A. L. and Smith, G. R. (1979a) Jovian upper atmospheric temperature measurement by the Voyager 1 UV spectrometer, Geophys. Res. Lett., 6, 795-798.

Atreya, S. K., Donahue, T. M. and Waite, J. H., Jr. (1979b) An interpretation of the Voyager measurement of Jovian electron density profiles, Nature, 280 , 795-796.

Atreya, S. K., Donahue, T. M. and Festou, M. C. (1980 or 81) Jupiter: structure and composition of the upper atmosphere, Astrophys. J. Lett., in press.

Barker, E. .S, Trafton, L. and Atreya, S. K. (1980) A spectroscopic search for $\mathrm{N}^{+}$emission in the polar regions of Saturn and on the nightside of Venus, Division of Planetary Scfences, Am. Astron. Soc. Meeting, Tucson, Arizona.

Bertaux, J. L., Festou, M., Barker, E. and Jenkins, E. (1980) Copernicus measurements of the Lyman Alpha albedo of Jup1ter, Astrophys. J., 238, 11521159.

Broadfoot, A. L., Belton, M. J. S,, Takacs, P. Z., Sandel, B. R., Shemansky, D. E., Holberg, J. B., Ajello, J. M., Atreya, S. K., Donahue, T. M., Moos, H. W., Bertaux, J. L., Blamont, J. E., Strobel, D. F., McConnell, J. C., Dalgarno, A., Goody, R. and McElroy, M. B. (1979) Extreme ultraviolet observations from Voyager 1 encounter with Jupiter, Science, 204, 979-982.

Broadfoot, A. L., Sandel, B. R., Shemansky, D. E., McConnell, J. C., Smith, G. R., Holberg, J. B., Atreya, S. K., Donahue, T. M., Strobel, D. F. and Bertaux, J. L. (1980) Overview of the Voyager ultraviolet spectrometry results through Jupiter encounter, J. Geophys. Res., in press.

Brown, R. A. (1974) Optical line emissions from Io; In: Exploration of the P1anetary System (Woszczyk, A. and Iwantszewska, C., Eds.) pp. 52 $\overline{7-5} \overline{31}$, D. Reidel Publishing Co., Dordrecht, Holland.

Carlson, R. W. and Judge, D. L. (1974) Pioneer 10 ultraviolet photometer observations at Jupiter encounter, J. Geophys. Res., 79, 2623-2633.

Clarke, J. T., Weaver, H. A., Feldman, P. D., Moos, H. W., Fastie, W. G. and Opal, C. B. (1980a) Spatial imaging of Hydrogen Lyman $\alpha$ emission from Jupiter, Astrophys. J. , preprint.

Clarke, J. T., Moos, H. W., Atreya, S. K. and Lane, A. L. (1980b) Aurora on Jupiter observed from earth orbit, Astrophys. J., 241, L179.

Cochran, W. D. and Barker, E. S. (1979) Variability of Lyman-Alpha emission from Jupiter, Astrophys. J., 234, L151.

Dessler, A. J., Sande1, B. R. and Atreya, S. K. (1980) The hydrogen bulge: evidence for corotating magnetospheric convection, Planet. Space Sci., in press.

Eshleman, V. R., Tyler, G. L., Wood, G. E., Lindal, G. F., Anderson, J. D., Levy, G. S. and Croft, T. A. (1979a) Radio science with Voyager 1 at Jupiter: preliminary profiles of the atmosphere and ionosphere, Science, 204, 976.

Eshleman, V. R., Tyler, G. L., Wood, G. E., Lindal, G. F., Anderson, J. D., Levy, G. S. and Croft, T, A. (1979b) Radio science with Voyager at Jupiter: 
Initial Voyager 2 results and a Voyager 1 measure of the Io torus, Science, 206, 959-962.

Elliott, J. L., Wasserman, L. H., Veverka, J., Sagan, C. and Liller, W. (1974) The occultation of Beta Scorpif by Jupiter 2. The hydrogen and helium abundance in the Jovian atmosphere, Astrophys. J., 190, 719-729.

Festou, M. C., Atreya, S. K., Donahue, T. M., Shemansky, D. E., Sandel, B. R. and Broadfoot, A. L. (1980) Composition and thermal profiles of the Jovian upper atmosphere determined by the Voyager ultraviolet stellar occultation experiment, J. Geophys. Res., in press. (See early 1981 issues, if not in 1980)

Fjeldbo, G., Kliore, A., Seldel, B., Sweetnam and Cain, D. (1975) The Pioneer 10 radio occultation measurements of the ionosphere of Jupiter, Astron. $\&$ Astrophys. , 39, 91-96.

Fjeldbo, G., Kliore, A., Seidel, B., Sweetnam and Wolceshyn, P. (1976) The Pioneer 11 radio occultation measurements of the Jovian ionosphere; In Jupiter (Gehrels, T., Ed.) pp. 238-245, Unfversity of Arizona Press, Tucson, Arizona.

French, R. G. and Gierasch, P. J. (1974) Waves in the Jovian upper atmosphere, J. Atmos. Sci., 31, 1707-1712.

Giles, J.W., Moos, H. W. and McKinney, W. R. (1976) The far-ultraviolet (1200$1900 \AA$ ) spectrum of Jupiter obtained with a rocket-borne multichannel spectrometer, J. Geophys. Res., 81, 5797-5806.

Hanel, R. A., Conrath, B., Flaser, M., Kunde, V., Lowman, P., Maguire, W., Pearl, J., Pirraglia, J., Samuelson, R., Gautier, D., Gierasch, P., Kumar, S. and Ponnamperuma, C. (1979) Infrared observations of the Jovian system from Voyager 1, Science, 204, 972-976.

Henry, R. J. W. and McElroy, M. B. (1969) The absorption of extreme ultravlolet solar radiation by Jupiter's upper atmosphere, J. Atmos. Sci., 26, 912.

Hunt, G. E. and Muller, J. P. (1979) Voyager observations of sma11-scale waves in the equatorial region of the Jovian atmosphere, Nature, 280, 778-780.

Hunten, D. M. (1969) The upper atmosphere of Jupiter, J. Atmos. Sci., 26, 826834.

Hunten, D. M. (1976) Atmospheres and Ionospheres; In: Jupiter (Gehrels, T., Ed.) pp. 22-31, University of Arizona Press, Tucson, Arizona.

Hunten, D. M. and Veverka, J. (1976) Stellar and spacecraft occultations by Jupiter: a critical review of derived temperature profiles; In: Jupiter (Gehrels, T., Ed.) p. 247, University of Arizona Press, Tucson, Arizona.

Hunten, D. M. and Dessler, A. J. (1977) Soft electrons as a possible heat source for Jupiter's thermosphere, Planet. Space Sci., 25, 817-821.

McConnell, J. C., Sandel, B. R. and Broadfoot, A. L. $(1980 \mathrm{a})$ Airglow from Jupiter's nightside and crescent: ultraviolet spectrometer observations from Voyager 2, Icarus, 43, 128.

McConne11, J. C., Sandel, B. R. and Broadfoot, A. L. (1980b) Voyager UV spectrometer observations of He $584 \AA$ dayglow at Jupiter, Planet. Space Sci., in press.

McElroy, M. B. (1973) The ionospheres of the major planets, Space Sci. Rev., $14,460-473$.

Moos, H. W., Fastie, W. G. and Bottema, M. (1969) Rocket measurement of ultraviolet spectra of Venus and Jupiter between 1200 and $1800 \AA$, Astrophys. J., $155,887$.

Mount, G. H., Warden, E. S. and Moos, H. W. (1977) Photoabsorption cross sections of methane from 1400-1850A, Astrophys. J., 214, L47-L49.

Mount, G. H. and Moos, H. W. (1978) Photoabsorption cross sections of methane and ethane, Astrophys. J., 224, L35-L37.

Nagy, A. F., Chameides, W. L., Chen, R. H. and Atreya, S. K. (1976) Electron temperatures in the Jovina ionosphere, J. Geophys. Res., 81, 5567-5569.

Okabe, H. and Becker, D. A. (1963) Vacuum-ultraviolet photochemistry, VII, photolysis of n-butane, J. Chem. Phys., 39, 2549-2555.

Rottman, G., Moos, H. W. and Freer, C. S. (1973) The far-ultraviolet spectrum of Jupiter, Astrophys. J., I84, L89.

Sandel, B. R., Shemansky, D. E., Broadfoot, A. L., Bertaux, J. L., Blamont, J. E., Belton, M., Ajello, J., Holberg, J., Atreya, S., Donahue, T., Moos, H., Strobel, D., McConnell, M., Dalgarno, A., Goody, R., McElroy, M. and Takacs, P. (1979) Extreme ultraviolet observations from Voyager encounter with Jupiter, Science, 206, 962-966.

Sande1, B. R., Broadfoot, A. L. and Strobel, D. F. (1980) Discovery of a longitudinal asymmetry in the hydrogen Iyman-alpha brightness of Jupiter, Geophys. Res. Lett., 7, 5.

Sato, M. and Hansen, J. E. (1979) Jupiter's atmospheric composition and cloud structure deduced from absorption bands in reflected sunlight, J. Atmos. Sci., 36, 1133 .

Shemansky, D. E., McConnell, J. C., Sandel, B. R. and Broadfoot, A. L. (1980) Excitation of $\mathrm{H}_{2}$ Lyman and Werner bands on Jupiter, in preparation. 
Strobel, D. F. (1973) The photochemistry of $\mathrm{NH}_{3}$ in the Jovian atmosphere, J. Atmos. Sci. , 30, 1205-1209.

Strobel, D. F. (I.975) Aeronomy of the major planets. Photochemistry of ammonia and hydrocarbons, Rev. Geophys. Space Phys., 13, 372-382.

Strobe1, D. F. (1979) The ionosphere of the major planets. Rev. Geophys. Space Phys., 17 .

Wallace, L. and Hunten, D. M. (1973) The Lyman alpha albedo of Jupiter, Astrophys. J., 182, 1013-1031.

Yung, Y. L. and Strobe1, D. F. (1980) Hydrocarbon photochemistry and Lymanalpha albedo of Jupiter, Astrophys. J., In press. 